\title{
Sinergismo de misturas de glyphosate e herbicidas inibidores da PROTOX no controle de corda- de-viola
}

Synergism of mixtures of glyphosate and PROTOX inhibitor herbicides for morning-glory control

\author{
Mauricio Crestani Agostineto', Leonardo Bianco de Carvalho ${ }^{1 *}$, Humberto Henrique Ansolin ${ }^{1}$, Thiago \\ Cavalcante Gomes Ribeiro de Andrade ${ }^{1,2}$ e Rodolfo Schmit ${ }^{1}$
}

Recebido em 05/10/2015 / Aceito em 30/11/2015.

\section{RESUMO}

As plantas daninhas podem causar perdas significativas de produtividade na agricultura, dentre as quais se destacam as cordas-de-viola (Ipomoea spp.) em diversos cultivos. Para seu controle podem ser utilizados herbicidas inibidores da enzima protoporfirinogênio IX oxidase em complementação ao glyphosate, ao qual essa planta daninha é tolerante. O objetivo foi testar a eficácia de aplicações isoladas e em mistura de glyphosate (Roundup Original ${ }^{\circledR}$ ) com carfentrazone-ethyl (Aurora $\left.{ }^{\circledR}\right)$ e saflufenacil (Heat $\left.{ }^{\circledR}\right)$ no controle de I. hederifolia em dois estádios de desenvolvimento da planta daninha. Os tratamentos foram: aplicação isolada de (i) carfentrazone-ethyl (50 e $75 \mathrm{~mL}$ p.c. ha-1), (ii) saflufenacil (35 e $50 \mathrm{~g}$ p.c. ha $\left.{ }^{-1}\right)$, e (iii) glyphosate (2 e 4 L p.c. ha $\left.{ }^{-1}\right)$; e em mistura de (iv) carfentrazone-ethyl+glyphosate e (v) saflufenacil+glyphosate (ambos na menor dose). As aplicações ocorreram em plantas de 6-8 folhas e 1520 folhas, mantendo-se testemunhas sem aplicação para esses dois estádios. A mistura dos herbicidas carfentrazone-ethyl e saflufenacil com glyphosate proporciona aumento na eficácia de controle de $I$. hederifolia, em relação à aplicação dos herbicidas isolados. A mistura de glyphosate+carfentrazoneethyl na dose de $2 \mathrm{~L} \mathrm{ha}^{-1}+50 \mathrm{~mL} \mathrm{ha}^{-1}$ proporciona controle mais eficaz e mais rápido de $I$. hederifolia, principalmente quando as plantas estão no estádio de 6-8 folhas.

PALAVRAS-CHAVE: Ipomoea hederifolia, planta daninha, controle químico, mistura em tanque.

\section{ABSTRACT}

Weeds can cause significant agricultural yield losses, and the morning-glory species (Ipomoea spp.) has stood out in several crops. To control morning-glories we can use herbicides inhibiting the protoporphyrinogen IX oxidase enzyme in addition to glyphosate, a herbicide that this weed is intolerant to. The objective was to test the efficacy of application of isolates and mixtures of glyphosate (Roundup Original ${ }^{\circledR}$ ) with carfentrazone-ethyl (Aurora ${ }^{\circledR}$ ) and saflufenacil (Heat $\left.{ }^{\circledR}\right)$ to control I. hederifolia in two weed growth stages. Treatments consisted of: isolated application of (i) carfentrazone-ethyl (50 and $75 \mathrm{~mL}$ 1.h. ha ${ }^{-1}$ ), (ii) saflufenacil (35 and $50 \mathrm{~g}$ 1.h. ha- ${ }^{-1}$, and (iii) glyphosate (2 and 4 L 1.h. ha ${ }^{-1}$; and mixtures of (iv) carfentrazone-ethyl+glyphosate and (v) saflufenacil+glyphosate (both in the lowest dose). Applications were performed on plants with 6-8 and 15-20 leaves, maintaining herbicide-free checks for both plant growth stages. Mixture of carfentrazoneethyl and saflufenacil with glyphosate increases the efficacy of control of $I$. hederifolia, compared to herbicide isolate applications. Mixture of $2 \mathrm{~L} \mathrm{ha}^{-1}+50$ $\mathrm{mL} \mathrm{ha-1}$ of glyphosate + carfentrazone-ethyl provides more efficient and faster control of I. hederifolia, mainly when the plants have 6-8 leaves.

KEYWORDS: Ipomoea hederifolia, weed, chemical control, tank mixture.

\section{INTRODUÇÃO}

Plantas daninhas caracterizam-se por interferirem no crescimento e desenvolvimento das plantas cultivadas (LAMEGO et al. 2015). A

${ }^{1}$ Universidade do Estado de Santa Catarina, Lages, SC, Brasil.

${ }^{2}$ Universidade Federal do Pará, Altamira, PA, Brasil.

*Autor para correspondência <leonardo.carvalho@udesc.br>. 
interferência de plantas daninhas na produtividade dos cultivos agrícolas é um dos principais fatores bióticos que limitam a produção de alimentos no mundo. Dentre os fatores de interferência, a competição interespecífica entre as plantas daninhas e as culturas agrícolas ocorre quando há limitação de recursos no meio, tais como os nutrientes, a luz, a água e o espaço (VARGAS \& ROMAN 2008). Dessa maneira, há necessidade de controle das plantas daninhas para prevenir perdas de produtividade e, assim, garantir a produção de alimentos.

As espécies da família Convolvulaceae são problema em diversos cultivos agrícolas, pois, interferem, diretamente, na produtividade por meio da competição por recursos ambientais e, indiretamente, na colheita, devido a seus ramos se entrelaçarem aos colmos, bloqueando o cilindro das colhedoras e, assim, comprometendo o rendimento e a eficiência da colheita (SILVA et al. 2015). Dentre as plantas daninhas desta família, pode ser destacada a Ipomoea hederifolia L. que ocorre em cultivos de cana-deaçúcar, crotalária, milho, sorgo (CARVALHO et al. 2014, GOMES et al. 2014, SILVA et al. 2015), entre outros.

O método de controle mais utilizado para o manejo de corda-de-viola é a aplicação de herbicidas. Dentre os herbicidas mais eficazes, destacam-se alguns inibidores da enzima protoporfirinogênio IX oxidase, com o carfentrazone-ethyl e o saflufenacil (LORENZI 2014). O herbicida glyphosate, apesar de ser um herbicida de ação total, deve ser utilizado apenas em pós-emergência inicial da corda-de-viola, pois apresenta pouca eficácia quando as plantas estão em estádios mais avançados de crescimento. No entanto, a mistura de herbicidas pode ser interessante e proporcionar melhor controle desta planta daninha, conforme observado por CORREA \& BORGES (2000), OLIVEIRA JÚNIOR et al. (2000), WERLANG \& SILVA (2002), RAMIRES et al. (2010), CONSTANTIN et al. (2011) e PICCININI et al. (2012).

A mistura de herbicidas torna-se promissora no controle de plantas daninhas, uma vez que, pode demonstrar aumento do número de espécies controladas dentro do complexo florístico infestante (VIEIRA JÚNIOR et al. 2015). Ademais, pode ser considerada uma prática benéfica na prevenção de plantas daninhas resistentes (OWEN \& ZELAYA 2005) ou mesmo tolerantes (VIEIRA JUNIOR et al. 2015) a herbicidas, principalmente quando se utilizam misturas de herbicidas com mecanismos de ação diferentes (KRUSE et al. 2000). Todavia, o uso conjunto de princípios ativos em mistura de tanque pode provocar efeitos adversos sobre as plantas daninhas e a cultura e, assim, tornam-se indispensáveis pesquisas sobre as prováveis interações entre herbicidas e sua eficácia, apontando ao uso adequado desses produtos (VIEIRA JUNIOR et al. 2015).

Segundo COLBY (1967), quando a resposta da mistura de herbicidas é maior que a esperada, a mistura é sinergística; quando é menor que a esperada, é antagonística e quando igual, aditiva. Despertam particular interesse as misturas que apresentam sinergismo, pois permitem o uso de doses menores e controlam plantas daninhas resistentes (GRESSEL 1990). Esse sinergismo, muitas vezes, ocorre quando são misturados dois herbicidas que apresentam diferentes mecanismos de ação, nos quais pode haver uma ação de complementaridade entre os mesmos, com um facilitando a ação física e ou bioquímica do outro (MATTHEWS 1994). Dessa forma, a mistura de herbicidas no tanque de pulverização, além dos benefícios supracitados, pode ainda reduzir o custo de pulverização e possibilidade de redução da dose recomendada, consequentemente a redução de resíduos no solo e da toxicidade à cultura de interesse (MACHADO et al. 2006, QUEIROZ et al. 2014).

O objetivo com o presente trabalho foi testar a eficácia de aplicações isoladas e em mistura de glyphosate com carfentrazone-ethyl e saflufenacil no controle de I. hederifolia em dois estádios de desenvolvimento da planta daninha.

\section{MATERIAL E MÉTODOS}

Plantas jovens de I. hederifolia cresceram durante outubro e dezembro de 2013, em área experimental do CAV/UDESC, em vasos de 5 litros preenchidos com mistura de solo e substrato orgânico na proporção de 4:1 (v:v). O solo utilizado apresentou as seguintes características: $54 \%$ de argila; $3,8 \%$ de M.O.; $\mathrm{pH}_{\text {(água) }}=5,1 ; \mathrm{SMP}=5,0$; teores de $\mathrm{P}, \mathrm{Na}$ e K de $2,9,10$ e $80 \mathrm{mg} \mathrm{dm}^{-3}$, respectivamente; teores de $\mathrm{Ca}$, $\mathrm{Mg} \mathrm{Al}, \mathrm{H}+\mathrm{Al}$ e $\mathrm{CTC}_{\text {efetiva }}$ de 4,63, 3,49, 1,36 13,70 e $9,68 \mathrm{cmol}_{\mathrm{c}} \mathrm{dm}^{-3}$, respectivamente; e saturação de $\mathrm{Al}$ e Bases de 14,05 e $37,80 \%$, respectivamente.

Antes da semeadura foram aplicados dois gramas de formulação de adubo 5-20-10 e três gramas de ureia. Depois da semeadura, as plantas foram diariamente irrigadas com $150 \mathrm{~mL}$ de água. Duas 
plantas cresceram em cada vaso e os vasos foram mantidos sob condições ambientais (temperatura do ar média de $16{ }^{\circ} \mathrm{C}$, umidade relativa média de $77 \%$ e precipitação acumulada de $187 \mathrm{~mm}$ ) durante todo experimento.

Os tratamentos consistiram na aplicação de herbicidas e misturas, sob condições ambientais favoráveis (temperatura de $18{ }^{\circ} \mathrm{C}$, umidade relativa do ar de $80 \%$ e poucas nuvens), utilizando pulverizador costal pressurizado a $\mathrm{CO}_{2}$, munido de barra com quatro bicos equipados com pontas de jato plano (TeeJet, 80,02, EUA), a pressão de $1,90 \mathrm{kgf} \mathrm{cm}^{-2}$ e o volume de calda de $200 \mathrm{~L} \mathrm{ha}^{-1}$. Os tratamentos foram: aplicação isolada de (i) carfentrazone-ethyl (Aurora ${ }^{\circledR}$, 400 g i.a. $\mathrm{L}^{-1}, \mathrm{FMC}$, Brasil), nas doses de 50 e 75 $\mathrm{mL}$ de produto comercial por hectare (p.c. ha ${ }^{-1}$ ), (ii) saflufenacil (Heat ${ }^{\circledR}, 700$ g i.a. $\mathrm{kg}^{-1}$, Basf, Brasil), nas doses de 35 e 50 g p.c. ha ${ }^{-1}$, (iii) glyphosate (Roundup Original ${ }^{\circledR}, 480$ g i.a. L $\mathrm{L}^{-1}$, Monsanto, Brasil), nas doses de 2 e 4 L p.c. ha ${ }^{-1}$; e em mistura, de (iv) carfentrazone-ethyl+glyphosate $\left(50 \mathrm{~mL}\right.$ p.c. $\mathrm{ha}^{-1}+2 \mathrm{~L}$ p.c. ha $\left.{ }^{-1}\right)$ e (v) saflufenacil + glyphosate $\left(35\right.$ g p.c. ha ${ }^{-1}$ +2 L p.c. ha $^{-1}$ ). As doses utilizadas correspondem a doses médias recomendadas pelos fabricantes para a maioria das culturas registradas (MAPA 2015 a,b). Os herbicidas isolados e as misturas de herbicidas foram aplicados sobre plantas em dois estádios de crescimento distintos, com 6-8 folhas e 15-20 folhas. Uma testemunha sem aplicação foi mantida para cada estádio. Utilizaram-se quatro repetições para cada tratamento.

Este experimento apresentou fatores com relação aninhada e cruzada. Dentro das épocas de avaliação, todos os herbicidas e doses adotadas foram avaliados, portanto a época possui uma relação cruzada com esses fatores. No entanto, não foram aplicadas diferentes doses nos tratamentos com mistura de herbicidas, assim como na testemunha. A relação herbicida e dose é aninhada, pois todos os níveis de dose não estão submetidos a todos os tratamentos químicos adotados (RIBEIRO \& CATEN 2011). Dessa forma, o modelo estatístico utilizado para explicar adequadamente o comportamento dos dados foi:

$\mathrm{Y}_{\mathrm{ijkl}}=\mu+$ época $_{\mathrm{i}}+$ herbicida $_{\mathrm{j}}+$ época*herbicida $_{\mathrm{ij}}+$ dose (herbicida) $)_{\mathrm{k}(\mathrm{j})}+$ época*dose (herbicida) $+\varepsilon_{\mathrm{ijk}}$

Em que: $Y_{\mathrm{ijk}}$ é a l-ésima observação no i-ésimo nível do fator época, j-ésimo nível do fator herbicida e k-ésimo nível do fator dose; $\mu$ é a média geral esperada; época ${ }_{\mathrm{i}}$ é o efeito devido ao i-ésimo nível do fator época; herbicida: é o efeito devido ao j-ésimo nível do fator herbicida; época*herbicida ${ }_{\mathrm{ij}}$ : efeito devido à interação do i-ésimo nível do fator época com j-ésimo nível do fator herbicida; dose (herbicida) $\mathrm{k}_{(\mathrm{j})}$ : é o efeito devido ao k-ésimo nível do fator dose hierarquizado sob o j-ésimo nível do fator herbicida; época*dose (herbicida): efeito devido à interação do i-ésimo nível do fator época com k-ésimo nível do fator dose hierarquizado sob o j-ésimo nível do fator herbicida; e $\varepsilon_{\mathrm{ijkl}}$ é o efeito do erro experimental.

Foi avaliada a data a partir da qual ocorreu a morte das plantas e, aos 14 dias após a aplicação dos herbicidas, as plantas foram cortadas rente ao solo e secas por 96 horas em estufa de circulação forçada de ar a $60{ }^{\circ} \mathrm{C}$. Depois de secas, as plantas foram pesadas em balança analítica $(0,001 \mathrm{~g})$ para determinação da massa seca. Os dados de massa seca foram transformados em porcentagem relativa à testemunha sem aplicação de herbicida para realização da análise estatística.

Foi efetuada a análise de variância para o caráter porcentagem relativa de massa seca em relação à testemunha sem aplicação, a 5\% de probabilidade. Em caso de fatores com efeito significativo, foi utilizado o teste de Scott-Knott para comparação das médias dos tratamentos. Para estas análises, utilizouse o programa computacional SAS ${ }$ (SAS Institute, versão 9.2, EUA).

\section{RESULTADOS}

$\mathrm{O}$ fator aninhado dose (herbicida) foi significativo $(\mathrm{p}<0,001)$, indicando que há resposta diferencial dos herbicidas usados e misturas testadas, aplicados em diferentes doses (Tabela 1). Além disso, isoladamente, o fator estádio também foi significativo $(\mathrm{p}<0,001)$, indicando que a eficácia de aplicação dos herbicidas é afetada pelo estádio de desenvolvimento das plantas.

Plantas de I. hederifolia com 15-20 folhas, submetidas à aplicação dos herbicidas em diferentes doses e das misturas de herbicidas, apresentaram $55,9 \%$ da massa seca acumulada em relação à testemunha, enquanto as plantas com 6-8 folhas, apresentaram massa seca acumulada de 33,9\% (Tabela 2), indicando que plantas em estádio mais avançado de desenvolvimento acumularam mais massa e foram, portanto, controladas com menor 
eficácia com a aplicação dos herbicidas e das misturas testadas, quando comparadas a plantas em estádio menos avançado de desenvolvimento.

Comparando os herbicidas, as diferentes doses aplicadas e as misturas, verificou-se que os herbicidas glyphosate e saflufenacil, aplicados de maneira isolada e em menor dose, proporcionaram maior acúmulo de massa seca $(57,1 \%$ e $55,4 \%$, respectivamente), em relação à testemunha (Tabela $3)$, sendo, portanto, menos eficazes no controle de I. hederifolia. O herbicida carfentrazone-ethyl (em menor dose) e o herbicida saflufenacil (em maior dose) proporcionaram o segundo maior acúmulo de massa seca $(43,0 \%$ e $42,8 \%$, respectivamente), em relação à testemunha. Os herbicidas glyphosate e carfentrazone-ethyl (em maior dose) e a mistura glyphosate+saflufenacil proporcionaram o segundo menor acúmulo de massa seca $(36,6 \%, 30,7 \%$ e $27,7 \%$, respectivamente), em relação à testemunha, apresentando, portanto, o segundo melhor controle. A mistura glyphosate + carfentrazone-ethyl proporcionou o menor acúmulo de massa seca $(20,1 \%)$, em relação à testemunha, indicando que a aplicação desta mistura foi mais eficaz no controle de I. hederifolia. Destacase que em todos os tratamentos com herbicidas ocorreu morte das plantas, mas em períodos diferentes após a aplicação, sendo que a mistura de glyphosate+carfentrazone-ethyl proporcionou o controle mais rápido e eficaz de I. hederifolia, com morte das plantas com quatro dias após a aplicação (Tabela 3).

\section{DISCUSSÃO}

A eficácia de controle de plantas daninhas é dependente do uso de misturas ou associações de herbicidas. Neste trabalho, verificou-se que os três herbicidas testados (glyphosate, carfentrazoneethyl e saflufenacil), quando aplicados de maneira isolada, apresentaram eficácia inferior à quando se aplicou mistura de glyphosate+carfentrazoneethyl ou glyphosate+saflufenacil (Tabela 3). Essas misturas proporcionaram controle mais rápido e mais intenso que as aplicações isoladas, principalmente quando foram misturados os herbicidas glyphosate e carfentrazone-ethyl.

A eficácia de misturas de herbicidas pode ser observada em diversos estudos realizados, como, por exemplo, o trabalho de INOUE et al. (2012), onde a eficiência da associação de herbicidas (glyphosate+ carfentrazone-ethyl e glyphosate+saflufenacil) sobre plantas adultas de Crotalaria spp. foi comprovada. RORATO et al. (2013), testando a eficácia do herbicida saflufenacil em um trabalho com Conyza spp., verificaram controle eficaz quando se misturou saflufenacil a glyphosate+imazethapyr, tendo inclusive, melhor efeito residual para o controle da planta daninha. VITORINO et al. (2012), avaliando a eficácia de diferentes herbicidas no controle de plantas daninhas dicotiledôneas na cultura da mamona, observaram que a mistura glyphosate + saflufenacil foi altamente eficaz no controle de $R$. brasilienses, Sida rhombifolia L. e I. grandifolia. Conforme observado por CORREA \& BORGES (2000), OLIVEIRA JÚNIOR et al. (2000), WERLANG \& SILVA (2002) e RAMIRES et al. (2010), a mistura de glyphosate com carfentrazone-ethyl aumentou a eficácia de controle de plantas daninhas, conforme descrito anteriormente, dentre outros motivos, segundo WERLANG \& SILVA (2002), por aumentar a velocidade de controle da planta daninha, conforme observado neste trabalho (Tabela 3).

Tabela 1 - Resumo da análise de variância sobre os tratamentos com diferentes herbicidas isolados e misturas, doses e estádios de crescimento de Ipomoea hederifolia.

Table 1 - Analysis of variance resume on treatments with different isolated herbicides and mixtures, doses, and plant growth stages of Ipomoea hederifolia.

\begin{tabular}{lccc}
\hline Causas de Variação & GL & F & P \\
\hline Herbicida (H) & 5 & 155,230 & $<0,001$ \\
Estádio (E) & 1 & 258,690 & $<0,001$ \\
H×E & 5 & 1,090 & 0,376 \\
Dose (Herbicida) & 3 & 22,340 & $<0,001$ \\
Estádio $\times$ Dose (Herbicida) & 3 & 1,060 & 0,375 \\
\hline
\end{tabular}


Tabela 2 - Média da porcentagem de massa seca de Ipomoea hederifolia, em relação à testemunha, em função do estádio de crescimento das plantas no momento da aplicação de diferentes herbicidas isolados (carfentrazone-ethyl, glyphosate e saflufenacil) e misturas de herbicidas (carfentrazoneethyl+glyphosate e saflufenacil+glyphosate).

Table 2 - Mean of the percentage of dry mass of Ipomoea hederifolia, in relation to the herbicide-free check, and function of plant growth stage at the time of application of different isolated herbicides (carfentrazoneethyl, glyphosate, and saflufenacil) and mixtures of herbicides (carfentrazone-ethyl + glyphosate and saflufenacil+glyphosate).

\begin{tabular}{lc}
\hline Estádio de Aplicação & Massa seca $^{1 /, 2}$ \\
\hline 6-8 folhas & $33,9 \mathrm{~B}$ \\
15-20 folhas & $59,4 \mathrm{~A}$ \\
$\frac{{ }^{1} \text { Os dados foram transformados em arcoseno } 2 \sqrt{\frac{x}{M S m a x}}}{}$ & para análise estatística, em que x corresponde à \\
porcentagem de massa seca da repetição em relação à porcentagem de massa seca média da testemunha e \\
MSmax corresponde à porcentagem máxima de massa seca da espécie. \\
${ }^{12}$ Médias com letras diferentes diferem entre si a 5\% de probabilidade pela análise de variância (teste $\left.\mathrm{F}\right)$.
\end{tabular}

Tabela 3 - Porcentagem de massa seca (MS) de Ipomoea hederifolia, em relação à testemunha, e período após a aplicação em que ocorreu morte das plantas, em função da aplicação de diferentes herbicidas, doses e misturas de herbicidas.

Table 3 - Percentage of dry mass (MS) of Ipomoea hederifolia, in relation to the herbicide-free check, and time of plant death after application (Morte), in function of application of different herbicides, doses, and mixtures of herbicides.

\begin{tabular}{lccc}
\hline Tratamento & Dose & $\mathrm{MS}^{/ 2,3}$ & $\begin{array}{c}\text { Morte } \\
\text { (dias) }\end{array}$ \\
\hline Testemunha & $\mathrm{NA}^{/ 1}$ & $100,0 \mathrm{~A}$ & - \\
Glyphosate & $2 \mathrm{~L} \mathrm{ha}^{-1}$ & $57,1 \mathrm{~B}$ & 12 \\
Saflufenacil & $35 \mathrm{~g} \mathrm{ha}^{-1}$ & $55,4 \mathrm{~B}$ & 10 \\
Carfentrazone-ethyl & $50 \mathrm{~mL} \mathrm{ha}^{-1}$ & $43,0 \mathrm{C}$ & 9 \\
Saflufenacil & $50 \mathrm{~g} \mathrm{ha}^{-1}$ & $42,8 \mathrm{C}$ & 9 \\
Glyphosate & $4 \mathrm{~L} \mathrm{ha}^{-1}$ & $36,6 \mathrm{D}$ & 8 \\
Carfentrazone-ethyl & $75 \mathrm{~mL} \mathrm{ha}^{-1}$ & $30,7 \mathrm{D}$ & 7 \\
Glyphosate+Saflufenacil & $2 \mathrm{~L} \mathrm{ha}^{-1}+35 \mathrm{~g} \mathrm{ha}^{-1}$ & $27,7 \mathrm{D}$ & 7 \\
Glyphosate+Carfentrazone-ethyl & $2 \mathrm{~L} \mathrm{ha}^{-1}+50 \mathrm{~mL} \mathrm{ha}^{-1}$ & $20,1 \mathrm{E}$ & 4 \\
\hline
\end{tabular}

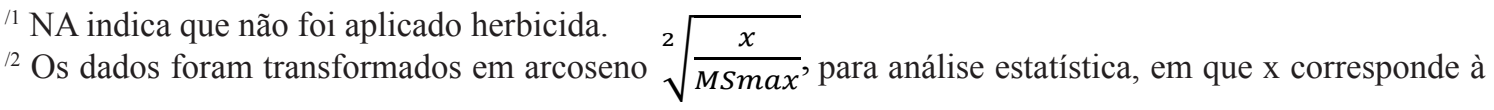

porcentagem de massa seca da repetição em relação à porcentagem de massa seca média da testemunha e MS max corresponde à porcentagem máxima de massa seca da espécie.

${ }^{13}$ Médias seguidas pela mesma letra não diferem entre si pelo teste de Scott-Knott a 5\% de probabilidade.

CONSTANTIN et al. (2011) e PICCININI et al. (2012) verificaram efeito similar com a mistura de glyphosate com saflufenacil.

Para plantas em estádio avançado de desenvolvimento, os níveis de controle tendem a reduzir, conforme observado por CONSTANTIN et al. (2013) no caso de plantas de buva superiores a
$15 \mathrm{~cm}$. Esse fato também foi verificado no presente trabalho, em que o controle de I. hederifolia com 1520 folhas foi menos eficaz do que com 6-8 folhas, independentemente do tratamento utilizado (Tabela 2). Segundo CONSTANTIN et al. (2013), no caso de buva maior de $15 \mathrm{~cm}$, aplicações sequenciais em intervalos cuidadosamente estabelecidos podem 
gerar melhores resultados, inclusive com o uso de saflufenacil. No caso da corda-de-viola, observouse, no presente trabalho, que o controle foi mais eficaz quando realizado sobre plantas com 6-8 folhas, utilizando-se da mistura de glyphosate com carfentrazone-ethyl.

A mistura de glyphosate com outros herbicidas tem demonstrado resultados de antagonismo ou sinergismo. Chlorimuron-ethyl foi compatível com glyphosate, porém o acifluorfen-Na demonstrou atividade antagônica no controle de Echinochloa crusgalli (L.) P. Beauv. (JORDAN et al. 1997). A mistura de pequenas doses de lactofen com glyphosate age sinergisticamente no controle de Malva parviflora L., porém misturas de lactofen em doses maiores provocam efeito antagônico, aparentemente pela destruição da membrana plasmática, ocasionando menor absorção de glyphosate (WELLS \& APPLEBY 1992). A mistura de oxyfluorfen com glyphosate melhorou o controle de Cyperus esculentus L., pois promoveu maior absorção de ${ }^{14} \mathrm{C}$-glyphosate por esta espécie (PEREIRA \& CRABTREE 1986).

A mistura de glyphosate com acifluorfen ou bentazon proporcionou melhor controle de dicotiledôneas, entretanto, o controle de gramíneas foi prejudicado em algumas condições, quando glyphosate foi usado em mistura com outros herbicidas (SELLECK \& BAIRD 1981, HYDRICK \& SHAW 1994). Segundo STARKE \& OLIVER (1998), a mistura em tanque de glyphosate com chlorimuronethyl foi caracterizada como aditiva e não reduziu a absorção e translocação de ${ }^{14} \mathrm{C}$-glyphosate em E. crusgalli, Ipomoea lacunosa L. e Abutilon theophrasti (L.) Rusby; enquanto as misturas de fomesafen com glyphosate foram antagônicas no controle dessas espécies, reduzindo a absorção e translocação de glyphosate, assim como sulfentrazone em mistura no tanque com glyphosate proporcionou efeito antagônico no controle de E. crus-galli, Amaranthus palmeri L., E. indica e Ipomoea hederacea var. integriuscula Jacq.

Outras misturas com glyphosate foram testadas, com resultados satisfatórios, como, por exemplo, sulfentrazone, flumioxazin e carfentrazone-ethyl, saflufenacil, entre outros (GARCIA\& NASCIMENTO 2000, GAZZIERO et al. 2000, SILVA \& COBUCCI 2000, WERLANG \& SILVA 2002).

Carfentrazone-ethyl, segundo WERLANG \& SILVA (2002), é uma molécula que possivelmente tenha características similares ao lactofen, quando misturado com glyphosate em pequenas doses (como no caso do presente trabalho em que foram utilizadas as doses mais baixas recomendadas, tanto do glyphosate quanto do carfentrazone-ethyl). Segundo WELLS \& APPLEBY (1992), lactofen interage com glyphosate melhorando a atividade deste na planta, por facilitar a movimentação de glyphosate via simplasto na planta. Segundo esses autores, lactofen em doses pequenas melhorou a captura de glyphosate para o interior celular, no entanto, esta ação é pouco relatada na literatura, possivelmente devido às doses mais altas utilizadas em campo, sendo comum o antagonismo da ação de glyphosate, quando em mistura (JORDAN et al. 1997, STARKE \& OLIVER 1998). No caso do saflufenacil, espera-se ação similar ao carfentrazoneethyl por serem herbicidas do mesmo mecanismo de ação.

Portanto, evidencia-se que o uso da mistura de glyphosate com carfentrazone-ethyl, principalmente, ou saflufenacil, aplicada em plantas de I. hederifolia em estádio de desenvolvimento mais precoce, proporciona melhor e mais rápido controle da planta daninha, mesmo utilizando as doses mais baixas recomendadas. Assim, para o controle de corda-de-viola, que é uma planta daninha tolerante ao glyphosate, as misturas deste herbicida com carfentrazone-ethyl ou saflufenacil são alternativas eficazes de controle.

\section{CONCLUSÕES}

A mistura dos herbicidas carfentrazone-ethyl e saflufenacil com glyphosate proporciona aumento na eficácia de controle de $I$. hederifolia, em relação à aplicação dos herbicidas isolados.

A mistura de glyphosate+carfentrazoneethyl na dose de $2 \mathrm{~L} \mathrm{ha}^{-1}+50 \mathrm{~mL} \mathrm{ha}^{-1}$ proporciona controle mais eficaz e mais rápido de I. hederifolia, principalmente quando as plantas estão no estádio de 6-8 folhas.

\section{REFERÊNCIAS}

CARVALHO LB et al. 2014. Estudo comparativo do acúmulo de massa seca e macronutrientes por plantas de Zea mays e Ipomoea hederifolia. Planta Daninha. 32: 99107.

COLBY SR. 1967. Calculating synergistic and antagonistic responses of herbicide combinations. Weeds. 15: 20-22.

CONSTANTIN J et al. 2011. Desempenho de Heat aplicado em dessecação antecedendo a semeadura da 
cultura do algodoeiro para controle de corda-de-ciola, trapoeraba e leiteiro. In. 8 CONGRESSO BRASILEIRO DE ALGODÃO. Anais... Campina Grande: Embrapa Algodão. p.869-874.

CONSTANTIN J et al. 2013. Manejo da buva na entressafra. In.: CONSTANTIN J et al. (Eds.). Buva: fundamentos e recomendações para manejo. Maringá: Omnipax Editora. p.41-64.

CORRÊA LEA \& BORGES A. 2000. Glyphosate + carfentrazone no controle de ervas problemas. In.: 22 CONGRESSO BRASILEIRO DA CIÊNCIA DAS PLANTAS DANINHAS. Anais... Londrina: SBCPD, 2000. p. 463.

GARCIA I \& NASCIMENTO E. 2000. Avaliação do herbicida carfentrazone-ethyl (Aurora $400 \mathrm{CE}$ ) em mistura com glyphosate e sulfosate no controle de plantas daninhas em semeadura direta. In: 22 CONGRESSO BRASILEIRO DA CIÊNCIA DAS PLANTAS DANINHAS. Anais... Londrina: SBCPD. p.121.

GAZZIERO DLP et al. 2000. Herbicide alternatives for 2,4-D in no-till cropping systems. In: 5 INTERNATIONAL WEED SCIENCE CONGRESS. Proceedings... Foz do Iguaçu: SBCPD. p.134.

GOMES DS et al. 2014. Supressão de plantas espontâneas pelo uso de cobertura vegetal de crotalaria e sorgo. Rev. Bras. Agroecol. 9: 206-213.

GRESSEL J. 1990. Synergizing herbicides. Rev. Weed Sci. 5: 49-82.

HYDRICK DE \& SHAW DR. 1994. Effects of tank-mix combinations of non-selective foliar and selective soil applied herbicides on three weed species. Weed Technol. 8: 129-133.

INOUE MK et al. 2012. Eficácia de herbicidas aplicados em plantas adultas de Crotalaria spectabilis e Crotalaria ochroleuca. Rev. Bras. Herbic.11: 148-158.

JORDAN DL et al. 1997. Influence of application variables on efficacy of glyphosate. Weed Technol. 11: 354-362.

KRUSE ND et al. 2000. Herbicidas inibidores do EPSPS: revisão de literatura. Rev. Bras. Herbic. 1: 139-146.

LAMEGO FP et al. 2015. Potencial de supressão de plantas daninhas por plantas de cobertura de verão. Comun. Sci. 6: 97-105.

LORENZI H. 2014. Manual de identificação e controle de plantas daninhas: plantio direto e convencional. Nova Odessa: Plantarum. 383p.

MACHADO AFL et al. 2006. Misturas de herbicidas no manejo de plantas daninhas na cultura do feijão. Planta Daninha. 24: 107-114.

MAPA - MINISTÉRIO DA AGRICULTURA PECUÁRIA E ABASTECIMENTO DO BRASIL. Sistema de Agrotóxicos Fitossanitários. Carfentrazone-ethyl. Ministério da Agricultura Pecuária e Abastecimento, Brasil. Disponível em: <http://agrofit.agricultura.gov.br>. Acesso em 07 mai. 2015a.

MAPA - MINISTÉRIO DA AGRICULTURA PECUÁRIA
E ABASTECIMENTO DO BRASIL. Sistema de Agrotóxicos Fitossanitários. Saflufenacil. Ministério da Agricultura Pecuária e Abastecimento, Brasil. Disponível em: <http://agrofit.agricultura.gov.br>. Acesso em 07 mai. $2015 b$.

MATTHEWS JM. 1994. Management of herbicide resistant weed populations. In: POWLES S \& HOLTUM J (Eds.). Herbicide resistance in plants: biology and biochemistry. Boca Raton: CRC. p.317-335.

OLIVEIRA JÚNIOR RS et al. 2000. Carfentrazone: novo herbicida para o manejo de Ipomoea grandifolia e Commelina benghalensis em áreas de semeadura direta de soja e milho. In: 22 CONGRESSO BRASILEIRO DA CIÊNCIA DAS PLANTAS DANINHAS. Resumos... Londrina: SBCPD. p.440.

OWEN MDK \& ZELAYA IA. 2005. Herbicide-resistant crops and weed resistance to herbicides. Pest. Manag. Sci. 61: 301-311.

PEREIRA W \& CRABTREE G. 1986. Absorption, translocation, and toxicity of glyphosate and oxyfluorfen in yellow nutsedge (Cyperus esculentus). Weed Sci. 34: 923929.

PICCININI F et al. 2012. Aplicações isoladas ou associadas de glifosato e saflufenacil para o controle de Ipomoea triloba e Ipomoea purpurea. Encicl. Biosf. 8: 150-159.

QUEIROZ JRG et al. 2014. Eficiência da aplicação da mistura de glyphosate com saflufenacil sobre plantas de Brachiaria decumbens. Rev. Bras. Herbic. 13: 1-7.

RAMIRES AC et al. 2010. Controle de Euphorbia heterophylla e Ipomoea grandifolia com a utilização de glyphosate isolado ou em associação com latifolicidas. Planta Daninha. 28: 621-629.

RIBEIRO JLD \& CATEN CST. 2011. Projeto de experimentos. Universidade Federal do Rio Grande do Sul: Porto Alegre. 153p.

RORATO DN et al. 2013. Eficiência do herbicida saflufenacil, no controle de Conyza spp. em dessecação pré-plantio da soja. Rev. Ciênc. Exatas Terra Ciênc. Agrár. 8: $1-8$.

SELLECK GW \& BAIRD DD. 1981. Antagonism of glyphosate and residual herbicide combinations. Weed Sci. 29: 185-190.

SILVA MVPP et al. 2015. Aplicação de herbicidas em pré-emergência sobre palha de cana-de-açúcar para o controle de espécies da família Convolvulaceae. Revista Agro@mbiente. 9: 184-193.

SILVA MA \& COBUCCI T. 2000. Herbicidas aplicados em pré-plantio no controle de plantas daninhas, na cultura do feijoeiro. In: 22 CONGRESSO BRASILEIRO DA CIÊNCIA DAS PLANTAS DANINHAS. Anais... Londrina: SBCPD. p. 235.

STARKE RJ \& OLIVER LR. 1998. Interaction of glyphosate with chlorimuron, fomesafen, imazethapyr, and sulfentrazone. Weed Sci. 46: 652-660.

VARGAS L \& ROMAN ES. 2008. Manual de Manejo e 
Controle de Plantas Daninhas. Passo Fundo: Embrapa Trigo. 779 p.

VITORINO HS et al. 2012. Eficiência de herbicidas no controle de plantas daninhas latifoliadas em mamona. Arq. Inst. Biol. 79: 129-133.

WELLS BH \& APPLEBY AP. 1992. Lactofen increases glyphosate-simulated shikimate production in little mallow (Malva parviflora). Weed Sci. 40: 171-173.

WERLANG RC \& SILVA AA. 2002. Interação de glyphosate com carfentrazone-ethyl. Planta Daninha. 20: 93-102. 